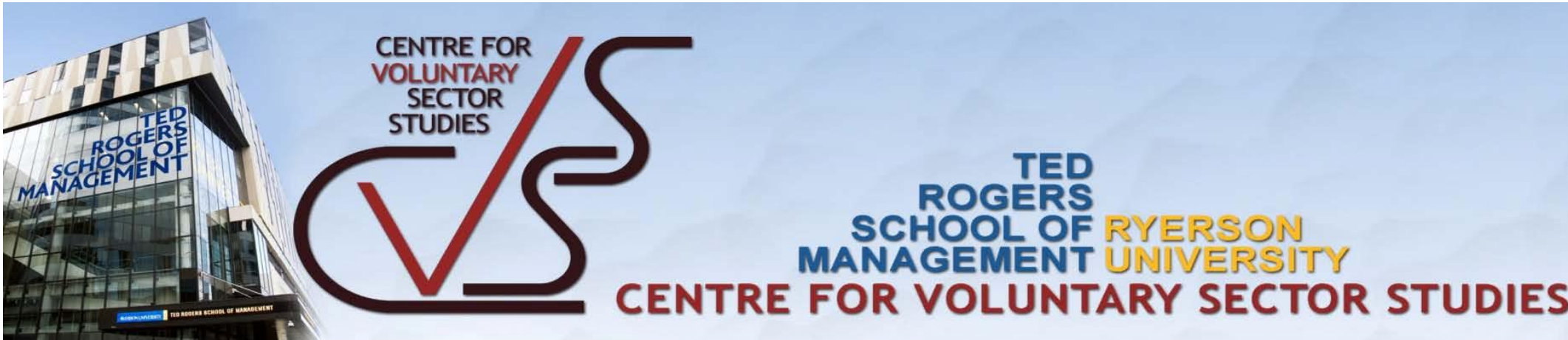

\title{
Ethnicity, Voluntary Behaviour and Social Integration ${ }^{1}$
}

\section{Ida Berger, Michaela Dinca-Panaitescu, Mary Foster and Agnes Meinhard}

Centre for Voluntary Sector Studies, Ryerson University

\section{Working Paper Series \\ Volume 2005 (1)}

350 Victoria Street

Toronto, Ontario, M5B 2K3

Tel: (416) 979-5000 x 6739 / Fax: (416) 979-5124

cvss@ryerson.ca

http://www.ryerson.ca/cvss/working_papers/

\footnotetext{
${ }^{1}$ The authors acknowledge the Social Sciences and Humanities Research Council for its financial support of this project; the staff at the Toronto Research Data Centre, and Statistics Canada for making the Ethnic Diversity Survey data available and supporting this work; and Leon Tai for the preliminary data analysis. However, all opinions and interpretations are those of the authors.
} 
Using data from the Ethnic Diversity Survey, this paper explores the relationship between volunteering and social integration and the moderating influence of ethnic subgroup identity and length of time in Canada on this relationship.

\section{Introduction}

The voluntary sector has long been seen as the foundation of a healthy civil society (DeTocqueville, 1961; Leonard \& Onyx, 2003). Yet, substantial growth in the last two decades in demand for voluntary sector services in Canada has been accompanied by a significant reduction in government resources supporting the sector's activities (Browne, 1996). This confluence of sector growth and decreased governmental support has resulted in increased competition among voluntary organizations for both capital and human resources (Meinhard \& Foster, 2000). Furthermore, the ethnic transformation of Canadian society raises knowledge, policy and practical issues across all sectors, including the voluntary sector. These conditions have pushed many in the voluntary sector to reach beyond their traditional bases of support to consider hitherto untapped segments of society. However, research on the Canadian voluntary sector, particularly with a cross-cultural lens, is a relatively new research domain, with many gaps in the knowledge base.

Berger (2004) and Berger \& Azaria (2004) have proposed, tested and supported a framework that traces the relationship between sub-group identity and volunteering, as mediated by attitudes, norms and social barriers. In this paper we extend this framework in order to consider the role of volunteering in social integration. (See Figure 1 below.) We use the 2002 Ethnic Diversity Survey (EDS) not only to investigate this relationship in general, but also to examine how it might be moderated by generation and ethnic identification.

\section{Conceptual Development}

As a multi-cultural country where diversity is celebrated and immigration a constant reality, Canada is composed of a growing number of citizens who define themselves as both Canadians and members of ethnic sub-cultures. Marketers across a wide array of organizations are recognizing that mass, un-segmented strategies that ignore population distinctions are no longer adequate. Voluntary sector research on age, gender, race, and religious activities (see, e.g., Musik et al., 2000, Goss 1999; Cnaan, Kasternakis, \& Wineburg, 1993) supports this position. For example, Reed and Selbee (2001), using the 1997 and 2000 NSGVP, demonstrate the importance of religion and religiosity in discriminating between those who are and those who are not civically active. However, the implications of ethnic diversity on attitudes, norms, voluntary behaviour, social processes and social integration in Canada have not been explicitly addressed. 
The framework depicted in Figure 1 below proposes that sub-group identity (ethnic identity for instance) influences volunteering attitudes, group specific subjective norms and group specific social barriers. It is through this mediated process that sub-group identity impacts rates of volunteering. Furthermore, the framework recognizes that volunteering is associated with broader social processes and consequences, and proposes that one important consequence is social integration. This complex concept includes not only processes that lead to the reduction of disparities in wealth and income, but also the benefits associated with living in a cohesive society, such as economic growth, peace, security, stability and social justice.

Figure 1: Hypothesized Framework

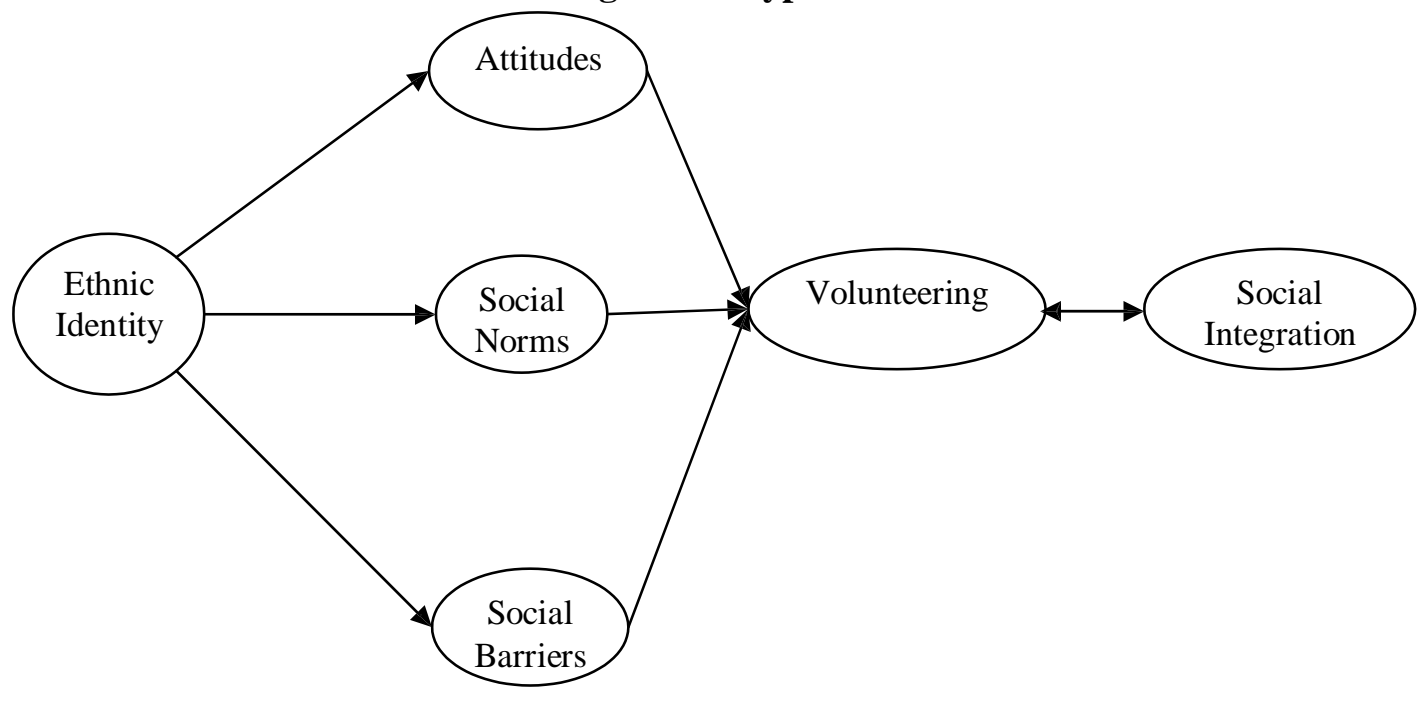

\section{Attitudinal Influences}

A large literature exists examining "cultural asymmetry" in preference and persuasion, implying that different behaviours are consistent with different cultural meanings (see Aaker, 2000, for a review). Marketing researchers examining the culturally distinct effects of different promotional appeals have found, for example, that North Americans are more responsive than others to messages associated with self-reliance, self-improvement, and the achievement of personal goals (Aaker, 2000). Because of diversity in traditions, religions, and histories, different cultures hold culturally distinct sets of values and beliefs. In addition, culturally distinct media, personal experiences, or social environments render culturally distinct beliefs more accessible. In the context of voluntary behaviour, the culturally asymmetric findings imply that the specific beliefs associated with volunteering, the way such beliefs are evaluated, and consequently the attitudes toward volunteering may vary by sub-group affiliation. Supporting this hypothesis, Berger (2004) found that variance in volunteering rates by religious, ethnic and visible minority categorizations can be traced to variance in attitudinal variables. For instance, high levels of giving and volunteering among conservative Protestants in Canada are significantly related to their feelings of altruism. 


\section{Normative Influences}

In addition to personal, within-individual factors, volunteering behaviour may be influenced by the norms and obligations of an individual's social network. The features of social organization that facilitate cooperation and collaboration for mutual benefit are referred to as "social capital" (Putnam, 1995). Social capital exists within and through structures of relationships that are based on norms of reciprocity, collective interest, individual obligation, and trustworthiness (Portes, 1998; Coleman, 1988). Portes (1998) recently presented a framework suggesting that individual identification with a group, recognition of a common fate, and feelings of "bounded solidarity" represent the antecedent sources of social capital. Applying this model to volunteering suggests that higher levels of culturally distinct identification (bounded solidarity) should lead to a stronger network of culturally distinct relationships (increased social capital) that in turn lead to higher levels of culturally distinct voluntary behaviour. Subjective norms in such a network would direct members to volunteer for the culturally distinct activities that are valued by the network. (See Berger \& Gainer, 2000 for support for this conceptualization in the U.S. Jewish community and Berger 2004 for support based on religion, ethnicity and visible minority status. )

\section{Facilitating/impeding Factors}

Diversity has been a mainstay in profiles of the Canadian population. Liberal immigration policies have resulted in a large proportion of citizens with ancestries other than our founding peoples (First Nations, English Protestants, and French Catholics). While we point regularly to our unique ability to integrate but still support diversity; there is evidence of social barriers faced by ethnic, religious, and visible minorities from as far back as World War I (Walker, 1989). Recent analyses also indicate that systematic segregation, discrimination, and marginalization based on sub-group identity exist in employment, housing, social services, and political participation. For example, the unemployment rate for visible minorities according to the 2001 Census was $9.5 \%$, compared to $7.4 \%$ for the total population. Social barriers may play a similar role in propensity to volunteer. In the voluntary domain, discrimination may take the form of some groups not being actively solicited, not being made aware of volunteering opportunities or not being approached in a culturally sensitive manner. For instance, being identified as a member of a particular ethnic group may increase the number of personal invitations to volunteer, increasing one's knowledge about where and how to volunteer, and thereby facilitating the volunteering decision. Being identified as a member of another group, or having no affiliation at all, may curtail the number of invitations received and may thereby impede the volunteering decision. Indeed, Berger (2004) found that what appears at first to be lower levels of charitable inclination on the part of some ethnic groups can be better understood in terms of social-structural impediments that serve as barriers to volunteering, especially for visible minorities.

\section{Social Integration as a Consequence of Voluntary Behavior}

If members of some sub-groups are systematically "outside" the mainstream voluntary sector, either because of their own attitudes, group norms, or social barriers, then they are 
excluded from the very processes through which their social and economic status might improve, and the processes through which they might integrate and contribute fully to Canadian society. While volunteering can be seen as a socially cohesive activity, and is often modeled as an integral part of social cohesion (Woolley, 1998), in order to understand the complex inter-relationship between volunteerism, social cohesion, and social integration, it is important to differentiate the processes (activities and mechanisms that reduce disparities in wealth and income), from the descriptions of an integrated, cohesive, society (such as a sense of generalized trust, high quality social networks, and reciprocity) and from the beneficial outcomes afforded by a cohesive, integrated society (such as socio-economic equity) (Berger-Schmitt, 2002). If volunteering represents a socially cohesive process, then higher levels of voluntary activity should be associated with higher levels of trust, stronger network ties, reciprocity and the like, and possibly higher levels of economic and other desirable benefits.

\section{Research Questions}

This study seeks to answer the following questions:

1. What is the relationship between volunteering and social integration, as measured by economic indicators of social success?

2. What influence do generation (length of time in Canada) and ethnic sub-group identity have on social success (as measured by economic indicators)?

\section{Method}

We used data from the 2002 Ethnic Diversity Survey (EDS) because it provides a comprehensive, detailed, national description of how and why Canadians choose to identify and acculturate. This survey was conducted by Statistics Canada in 9 languages with a national sample of 42,476 Canadians. It includes data on many of the critical constructs of interest to this paper, including respondent and family background, family and social interactions, social networks, socio-economic status, attitudes related to discrimination, trust and satisfaction, and some limited information about volunteering. For this study, the data were obtained through Statistics Canada, accessed and analyzed through the Research Data Centre at the University of Toronto.

We used the measurement framework proposed by Stone and Hughes (2002) to choose the variables of interest for this study. The first set of variables includes personal characteristics as Stone and Hughes see these factors as determinants of social capital.

- Ethnic sub-group identity. We operationalized this variable using the question: "What is your ethnic or cultural identity?" This study focuses on four, self-identified ethnic groups: AngloSaxon, East-European, Chinese, and South Asian.

- Strength of ethnicity. Two questions were used to estimate this variable: "How important is your identity to you?" and "How important is your ancestry to you?". Importance was measured on a 5-point scale with 1-not important at all to 5- very important. The mean value of these questions was used to represent the strength of ethnicity.

- Religiosity was captured as the mean value of two questions: the frequency of involvement in religious activities on a 5-point scale with 0-"not at all" to 4-"at least once a week" and the 
importance given to religion on 5-point scale ranging from 1-“no importance" to 5-"very important".

- Generation. Statistics Canada provided a derived variable that categorized the sample into first generation (not born in Canada), second generation (born in Canada, but parents not born in Canada), and third generation (both respondent and parents born in Canada).

The second set of questions asked about the nature of respondents' social networks - in particular feelings of trust and homogeneity. In the Stone and Hughes (2002) framework these constructs represent two key elements of social capital.

- Homogeneity of network index. Respondents were asked how many of their friends shared their ancestry, both now and up until they were age 15; how many members of their organizations and how many of their workmates shared their ancestry. Responses were measured on a 5-point scale from 1-"none of them" to 5-"all of them". The index created was the mean of these responses.

- Index of trust. Norms of trust governing these networks were quantified as the mean response to three questions referring to the degree of trust in: people in your family, people in your neighbourhood and people you work with or go to school with measured on a scale of 1"cannot be trusted at all", to 5 "can be trusted a lot", and a question regarding generalized trust measured on a 2-point scale of 1- "people can be trusted" and 2- "you cannot be too careful in dealing with people".

In the Stone and Hughes (2002) framework, like our own, one of the hypothesized outcomes of social capital is a vibrant civic life. We created two indices to gauge respondents' engagement with the voluntary sector.

- Participation index. Using two Yes/No questions regarding membership in and volunteering with voluntary organizations we created an index by posing the two questions simultaneously to generate a two-by-two frame with a 7-point scale: 0-"not member and no volunteering" to 6-"member in 3 organizations and volunteering in all 3".

- Number of types of organizations. We used a Statistics Canada derived variable that reported the "number of types of organizations involved in", ranging on a 4-point scale from "1 type of organization" to " 4 or more types of organizations"

The dependent variable for this study was defined as socio-economic success. This variable was based both on questions from the EDS survey and collated questions for the same respondent from the 2001 Census measuring "unemployment", "poverty", and "living conditions". The index of social success was calculated as the mean value of three measures:

- Unemployment. This measure is based on responses to main source of personal income and usual major activity. Respondents reporting main source of income as: "no income", "employment insurance", "child tax benefit", or "social assistance/welfare" or reporting main activity as: "looking for paid job", "caring for own children/other family members" or "volunteering" were considered unemployed.

- Poverty. The poverty measure was based on the low-income cut-offs set by Statistics Canada and on a question asking for the household income.

- Living conditions. This was calculated as the number of household inhabitants divided by the number of rooms in the living accommodation. 
Data were analyzed using linear regression procedures in SPSS. Confidentiality and disclosure regulations require that all analyses be conducted on weighted samples only. The weight used for all analyses is the general weighting factor supplied by Statistics Canada. Because of the magnitude of the resulting sample size (22+ million), all differences and all statistical tests are statistically significant at p-values at or below commonly accepted levels. In the following discussion, differences or findings that represent practically substantive variance are highlighted. Furthermore, because variance estimates found in statistical packages are not reliable for sample designs as complex as that used for the EDS, an efficient method to estimate true variances needed to be applied. Under the advice of Statistics Canada a bootstrap resampling methodology involving 500 weights was used in all reported analyses.

\section{Results}

Table 1 presents the regression results for the total sample. The data show that generalized trust, diversity of organizational involvement and participation in the voluntary sector, all dimensions of social bridging, all have a positive influence on social success. By contrast, homogeneity of social network, strength of ethnicity and religiosity, all dimensions of social bonding, have a negative influence on social success. At a generalized level, when issues

Table 1: Regression Coefficients for the Total Sample ( $p<.05$ for all)

\begin{tabular}{|l|l|c|}
\hline Social success as a function of: & Total Sample \\
\hline & Intercept & -.627 \\
\hline Personal & Strength of ethnicity & -.017 \\
Characteristics & Religiosity & -.021 \\
\hline Network Structure & Homogeneity of network & -.019 \\
and Norms & Index of trust & .047 \\
\hline Volunteering & Participating in the voluntary sector & .002 \\
& Number of kinds of organizations & .025 \\
\hline Other factors & Age & .005 \\
& Sex & -.077 \\
& Married & -.059 \\
& Widowed & -.028 \\
& Separated & -.012 \\
& Divorced & -.003 \\
& College/university graduate & .088 \\
& Some college & .062 \\
\hline
\end{tabular}

of age, sex, education and marital status are controlled, the results indicate that socially cohesive processes that provide an opportunity to bridge with other networks may result in more social integration than socially cohesive bonding processes.

These generalized results must be qualified by differences stemming from both generation in Canada and ethnicity. In particular, Table 2 indicates that the negative impact of homogeneity of network ties and religiosity is most pronounced for first generation Canadians. Similarly, the positive impact of engagement with the voluntary sector on social success is most pronounced for the first generation. 
Table 2: Regression Coefficients by Generation ( $p<.05$ for all)

\begin{tabular}{|c|c|c|c|c|}
\hline \multicolumn{2}{|c|}{ Social success as a function of: } & First & Second & Third \\
\hline & Intercept & -.739 & -.603 & -.649 \\
\hline Personal Characteristics & $\begin{array}{l}\text { Strength of ethnicity } \\
\text { Religiosity }\end{array}$ & $\begin{array}{l}-.013 \\
-.021\end{array}$ & $\begin{array}{l}-.002 \\
-.016\end{array}$ & $\begin{array}{l}-.003 \\
-.008\end{array}$ \\
\hline $\begin{array}{l}\text { Network Structure and } \\
\text { Norms }\end{array}$ & $\begin{array}{l}\text { Homogeneity of network } \\
\text { Index of trust }\end{array}$ & $\begin{array}{l}-.058 \\
.051 \\
\end{array}$ & $\begin{array}{l}-.018 \\
.028\end{array}$ & $\begin{array}{l}-.002 \\
.042\end{array}$ \\
\hline Volunteering & $\begin{array}{l}\text { Participating in the voluntary sector } \\
\text { Number of kinds of organizations }\end{array}$ & $\begin{array}{l}.016 \\
.014 \\
\end{array}$ & $\begin{array}{l}-.009 \\
.026\end{array}$ & $\begin{array}{l}-.013 \\
.037\end{array}$ \\
\hline Other factors & $\begin{array}{l}\text { Age } \\
\text { Sex } \\
\text { Married } \\
\text { Widowed } \\
\text { Separated } \\
\text { Divorced } \\
\text { College/university graduate } \\
\text { Some college } \\
\end{array}$ & $\begin{array}{l}.008 \\
-.070 \\
-.067 \\
-.031 \\
-.059 \\
.052 \\
.097 \\
.092 \\
\end{array}$ & $\begin{array}{l}.005 \\
-.071 \\
-.050 \\
-.031 \\
.028 \\
.010 \\
.122 \\
.078 \\
\end{array}$ & $\begin{array}{l}.004 \\
-.084 \\
-.025 \\
-.002 \\
.026 \\
-.005 \\
.082 \\
.048 \\
\end{array}$ \\
\hline
\end{tabular}

Table 3: Regression Coefficients by Ethnic Subgroup ( $p<.05$ for all)

\begin{tabular}{|l|l|c|c|c|c|}
\hline \multicolumn{2}{|c|}{ Social success as a function of: } & $\begin{array}{c}\text { Anglo- } \\
\text { Saxon }\end{array}$ & $\begin{array}{c}\text { East } \\
\text { European }\end{array}$ & $\begin{array}{c}\text { South } \\
\text { Asian }\end{array}$ & Chinese \\
\hline & Intercept & -.582 & -.447 & -.951 & .531 \\
\hline Personal & Strength of ethnicity & -.004 & -.043 & .060 & -.133 \\
Characteristics & Religiosity & -.005 & .003 & -.025 & -.018 \\
\hline Network Structure & Homogeneity of network & -.009 & -.020 & -.116 & -.077 \\
and Norms & Index of trust & .037 & .053 & .073 & -.087 \\
& & & & & \\
\hline Volunteering & Participating in the voluntary sector & -.004 & -.011 & .027 & .136 \\
& Number of kinds of organizations & .026 & .019 & .049 & -.234 \\
\hline Other factors & Age & .003 & .004 & .005 & .004 \\
& Sex & -.073 & -.111 & -.052 & -.136 \\
& Married & -.032 & -.073 & -.006 & -.048 \\
& Widowed & .001 & -.054 & -.028 & .100 \\
& Separated & .004 & .035 & -.214 & .010 \\
& Divorced & -.031 & .013 & .197 & .034 \\
& College/university graduate & .070 & .066 & .063 & .162 \\
& Some college & .034 & .024 & .098 & .037 \\
\hline
\end{tabular}

As Table 3 indicates, the factors that influence social success also differ by ethnic group. In particular we see that homogeneity of network and strength of ethnic identity has a negative impact on social success among Chinese Canadians. At the same time, engagement with the voluntary sector is positively related to social success among Chinese Canadians. Also worthy of comment is the fact that female Chinese Canadians have particularly low levels of social success. 


\section{Discussion and Conclusion}

The conceptual framework for this paper suggests that volunteering has an influence on social integration. Our results provide support for the proposed model in that they show that volunteering enhances social success for Canadians in general, and particularly first generation Canadians and Chinese Canadians. In addition, another feature associated with the development of social capital, notably generalized trust, is also positively associated with social success.

What is interesting about these results, however, is that other factors also associated with the development of social capital have a negative relationship with social success. In particular features that represent or promote in-group bonding (that is creating ties within a homogenous group), work against social success. These include the homogeneity of social network, the strength of ethnicity and religiosity.

As Leonard and Onyx (2003) point out volunteering and its associated socially cohesive attributes may be socially bonding or socially bridging. That is, the voluntary experience may strengthen network ties, trust, reciprocity, shared norms and social agency in either a bonding (within group) or bridging fashion (between groups). Strengthened in-group feelings of belonging, community connectedness, trust and support, without overlapping connections outside the group could lead to factionalized, segregated or marginalized communities - the opposite of social integration (Leonard \& Onyx, 2003, p. 202). Our data seem to indicate that it is the "bridging" outcomes of volunteering that positively affect social success. Indeed, the diversity of organizational involvement had a positive influence on social success, supporting the positive role of "bridging". To understand the relationship between volunteering and social integration therefore it is important to distinguish between "bridging" cohesion, which spans social cleavages, and "ghettoising" cohesion, which reinforces marginalization, segregation and social dis-integration (Ellis and Howlett, 2004).

These explorations suggest several avenues for further study. While engagement in the voluntary sector does seem to be associated with social cohesion, whether or not such cohesion results in positive social outcomes depends on i) whether the cohesion is of a bonding or bridging variety and depends on ii) the kind of outcome examined. This is reminiscent of Berry's (1997) immigrant acculturation framework in which he categorizes immigrant acculturation into a fourgroup typology based on strength of ethnic identity (bonding) and the extent of out-group participation (bridging). He labels his four resulting quadrants as integration, assimilation, segregation and marginalization. According to this model minority group integration, the most positive and inclusive strategy, depends on the desire to maintain aspects of one's own culture (bonding), while also interacting, connecting and having significant contact with the dominant culture (bridging). The framework implies a positive, additive influence of both bridging and bonding on social outcomes. While the results of this exploratory analysis found support for the positive impact of bridging (at least for some groups), the impact of bonding was consistently negative, challenging the implied valence of the typology and indeed challenging Canada's multicultural 'ideal'.

However, the outcome variable used in this study represents a very narrow, economic definition of social integration. While this is consistent with some conceptualizations (Balakrishnan \& Hou, 1999; Grant \& Sweetman, 2004), there is no consensus in the literature on 
the definition and use of the positively valued term 'integration'. Like us, some studies define successful integration in socioeconomic terms, others refer to social and psychological measures (Bourhis et al., 1997), or institutional measures (Klymka, 1998; Harles, 2004), and still others, use measures of demographic living patterns (Steinman \& Jaegar, 2000). At another level, some studies refer to integration of a whole group or cohort (Drever, 2004), while other studies examine success from an individual perspective (Bourhis et al., 1997). Clearly, voluntary sector engagement has a role to play in successful social integration, but a full understanding of that role awaits further theoretical and empirical attention.

\section{References:}

Aaker, Jennifer L., "Accessibility or Diagnosticity? Disentangling the Influence of Culture on Persuasion Processes and Attitudes", Journal of Consumer Research, 26, (March 2000), 340-357. Balakrishnan, T.R \& Hou, F., "Socioeconomic integration and spatial residential patterns of immigrant groups in Canada", Population Research and Policy Review, 18, (1999), 201-217.

Berger, Ida E., "The influence of ethnicity, religion and visible minority status on philanthropy in Canada", Centre for Voluntary Sector Studies Working Paper, Faculty of Business, Ryerson University, (2004).

Berger, Ida E. \& Azaria, Justin, "Visible minority status and philanthropy", Paper presented at ASAC Conference, Quebec City, Canada, (2004).

Berger, Ida E. \& Gainer, Brenda, "Identity, Communal Embeddedness and Philanthropy", Paper presented at the Fourth International Conference of the International Society for Third Sector Research, Dublin, Ireland, (2000).

Berger-Schmit, R., "Considering social cohesion in quality of life assessments: concept and measurement", Social Indicators Research, 58, (2002), 403-428.

Berry, J.W., "Immigration, acculturation, and adaptation", Applied Psychology: An International Review, 46(1), (1997), 5-68.

Bourhis, R.Y., Moise, L.C., Perreault, S. \& Seneca, S., "Towards an interactive acculturation model: A social psychological approach", International Journal of Psychology, 32 (6), (1997), 369-386.

Browne, Paul L., "Love in a Cold World? The Voluntary Sector in the Age of Cuts", Ottawa: Canadian Centre for Policy Alternatives, (1996).

Cnaan, R., Kasternakis, A., \& Wineburg, R.J., "Religious people, religious congregations, and volunteerism in human services: Is there a link?", Nonprofit and Voluntary Sector Quarterly,

22 (1), (1993), 33-51.

Coleman, James, "Social Capital in the Creation of Human Capital", American Journal of Sociology, 94 (Supplement), (1988), S95-S120.

DeToqueville, A., Democracy in America, New York: Shoken, 1961 (Originally published 1835).

Drever, A., "Separate spaces, separate outcomes? Neighbourhood impacts on minorities in

Germany", Urban Studies, 41 (8), (2004), 1423-1439.

Ellis, A. \& Howlett, S., "Volunteering for all? Exploring the link between volunteering and social exclusion", Report: Institute for Volunteering Research, London, (2004).

Goss, Kristin A., "Volunteering and the Long Civic Generation", Nonprofit and Voluntary Sector Quarterly, 28 (4), (1999), 378-415

Grant, H \& Sweetman, A., "Introduction to economic and urban issues in Canadian immigration policy”, Canadian Journal of Urban Research, 13 (10), (2004), 1-24.

Harles, J.C., "Immigrant integration in Canada and the United States", American Review of

Canadian Studies, 34 (2), (2004), 223-258.

Kymlicka, W., Finding our way: Rethinking ethnocultural relations in Canada, Oxford: Oxford University Press, 1998.

Leonard, R. \& Onyx, J. "Networking through loose and strong ties: an Australian qualitative study”, Voluntas, 14(2), (2003), 189-203. 
Meinhard, A.G. \& Foster, M. K., "Third Sector Strategic Responses to Canada's Changing Social, Political and Economic Climate: A Comparative Analysis", the Fourth International Conference of the International Society for Third Sector Research, Dublin, Ireland, (2000).

Musick, Marc A., Wilson, John, \& Bynum, William B., "Race and Formal Volunteering: The Differential Effects of Class and Religion", Social Forces, 78 (4), (2000), 1539-1571.

Portes, Alejandro, "Social Capital: Its Origins and Applications in Modern Sociology", Annual Review of Sociology, 24, (1998), 1-24.

Putnam, Robert D., "Bowling Alone: America's Declining Social Capital", Journal of Democracy, (January 1995), 65-78.

Reed, Paul B. \& Selbee, L. Kevin, "The Civic Core: Disproportionality in Charitable Giving, Volunteering, and Civic Participation", Nonprofit and Voluntary Sector Quarterly, 30 (4), (2001), 761-780.

Steinmann, G. \& Jager, M., "Immigration and integration: Nonlinear dynamics of minorities", Mathematical Population Studies, 9 (1), (2000), 62-82.

Stone, W. \& Hughes, J., "Social capital. Empirical meaning and measurement validity", Research Paper, Australian Institute of Family Studies, 27, (June 2002).

Walker, James W. St.G., "Race and Recruitment in World War I: Enlistment of Visible Minorities in the Canadian Expeditionary Force", Canadian Historical Review, LLX (1), (1989). Wooley, F., "Social cohesion and voluntary activity: making connections", CSLS Conference on the state of living standards and the quality of life in Canada, Ottawa, (1998). 